\title{
Necrotizing Mediastinitis Following Rabbit Bone Ingestion: A Case Report
}

\author{
Mohammad Abdi $^{1}$ (D), Mehran Tahrekhani2 ${ }^{2}$, Mohammad Reza Zeraati*3 iD
}

1. Dept. of Emergency and Critical Care, School of Nursing and Midwifery, Zanjan University of Medical Sciences, Zanjan, Iran

2. Dept. of Medical-Surgical Nursing, Abhar School of Nursing, Zanjan University of Medical Sciences, Zanjan, Iran

3. Dept. of Critical Care, Ayatollah Mousavi Hospital, School of Medicine, Zanjan University of Medical Sciences, Zanjan, Iran

\begin{tabular}{|c|c|}
\hline Article Info & ABSTRACT \\
\hline doi $10.30699 / j a m b s .28 .128 .166$ & \multirow{3}{*}{$\begin{array}{l}\text { Necrotizing mediastinitis is the most lethal type of mediastinitis and is caused by } \\
\text { neck fascia, esophageal, and mediastinal infections. Therefore, its early diagnosis is } \\
\text { crucial. This report presents the case of a } 49 \text {-year-old man who was suffering from } \\
\text { necrotizing mediastinitis due to prolonged esophageal rupturing after rabbit bone } \\
\text { ingestion diagnosed using infection assessments and imaging. After right lateral } \\
\text { posterior thoracotomy, the mediastinal abscess was debrided and drained. The rabbit } \\
\text { bones were then removed from the esophagus. Two drainage tubes and two } \\
\text { thoracotomy tubes were inserted into the mediastinal and pleural spaces, and a } \\
\text { jejunostomy tube was inserted. Varied clinical manifestations makes the diagnosis } \\
\text { hard and time-consuming. If early diagnosis, antibiotic therapy, thoracic surgery, } \\
\text { proper monitoring, CT-scan imaging for differential diagnosis, and intervention are } \\
\text { not initiated promptly, mediastinitis resulting from DNM can be lethal. }\end{array}$} \\
\hline $\begin{array}{l}\text { Received: 2019/09/22; } \\
\text { Accepted: 2019/12/05; } \\
\text { Published Online: 01 May 2020; }\end{array}$ & \\
\hline \multirow[t]{3}{*}{$\begin{array}{l}\text { Use your device to scan and read the } \\
\text { article online }\end{array}$} & \\
\hline & Keywords: Esophageal foreign body, Necrotizing mediastinitis, Septic shock \\
\hline & $\begin{array}{l}\text { Corresponding Information: } \\
\text { Mohammad Reza Zeraati; Dept. of Critical Care, Ayatollah Mousavi Hospital, School of } \\
\text { Medicine, Zanjan University of Medical Sciences, Zanjan, Iran } \\
\text { E-Mail: mohammadrezazeraati@zums.ac.ir }\end{array}$ \\
\hline (c) (1) (9) & $\begin{array}{l}\text { open-access article distributed under the terms of the Creative Commons Attribution-noncommercial } 4.0 \text { International License which permits } \\
1 \text { just in noncommercial usages with proper citation. }\end{array}$ \\
\hline
\end{tabular}

\section{Introduction}

Mediastinitis is a life-threatening infection of the mediastinal tissue. Depending on the cause, the disease can be infected or non-infected and acute or chronic (1). Mediastinitis often occurs after cardiac surgery or an esophageal rupture (2). Necrotizing mediastinitis is the most lethal type of mediastinitis and is caused by neck fascia, esophageal, and mediastinal infections (3). The mortality rate is high, with reports ranging from $11 \%$ to $40 \%$ (4). Necrotizing mediastinitis is a rare but very dangerous form of medicinal space disorder (5). The symptoms vary greatly but usually include chest pain, dyspnea, pleural and pericardial effusion, sore throat, sputum, coughing, chest tenderness, fever, and submandibular and neck edema (6). The standard treatment for deep neck and chest infections like mediastinitis is to manage the airway with intubation (2), cricothyroidotomy, and tracheostomy and to then drain infected abscesses from the neck (7), mediastinal space, and fascia (8). The purpose of this report is to describe a case of necrotizing mediastinitis caused by a foreign body.

\section{Case Report}

We present a case of a 49-year-old man with esophageal perforation associated with necrotizing mediastinitis. This patient was admitted to the emergency department of the Vali-e Asr Hospital of
Zanjan, Iran, on 19 February 2019. He had complaints of chest pain, dyspnea, a sore throat, sputum, and a cough. The patient's primary complaint was of chest pain and a sore throat for the previous eight days. The patient's vital signs upon admission were as follows: blood pressure of 120 over $80 \mathrm{mmHg}$, an oral temperature of $38^{\circ} \mathrm{C}$, a respiratory rate of 20 per minute, and a heart rate of 123 beats per minute. His ECG rhythm was sinus tachycardia. Thoracic and chest tenderness were also detected during a clinical examination. The patient had a history of uncontrolled diabetes mellitus II. Laboratory data are presented in Tables 1 and 2 .

Due to the chest pain and sinus tachycardia, an emergency consultation with a cardiologist was performed. According to the cardiologist's early assessment, cardiovascular problems were not the cause of the patient's chest discomfort. Therefore, the patient was advised to be assessed by infectious disease specialists. According to the order of infectious disease specialists, a chest CT-scan was performed. The imaging result revealed an esophageal penetrating lesion due to a foreign body (a bone segment) (Figures 1 and 2). For further evaluations and surgery, the patient was transferred to Ayatollah Mousavi Hospital of Zanjan, Iran, the center of surgery. 
After an initial evaluation at Ayatollah Mousavi Hospital, rabbit bone was detected as a source of esophageal damage based on an assessment of the patient's history. After right lateral posterior thoracotomy, the mediastinal abscess was debrided and drained. The rabbit bones were then removed from the esophagus. Two drainage tubes and two thoracotomy tubes were inserted into the mediastinal and pleural spaces, and a jejunostomy tube was inserted. After the surgery, the patient was transferred to the intensive care unit (ICU), and mechanical ventilation was performed. After that, broad-spectrum antibiotics were administered upon admission. There were a lot of pussy fluid secretions from all drains with signs of severe sepsis, which was ended without control septic shock and death.

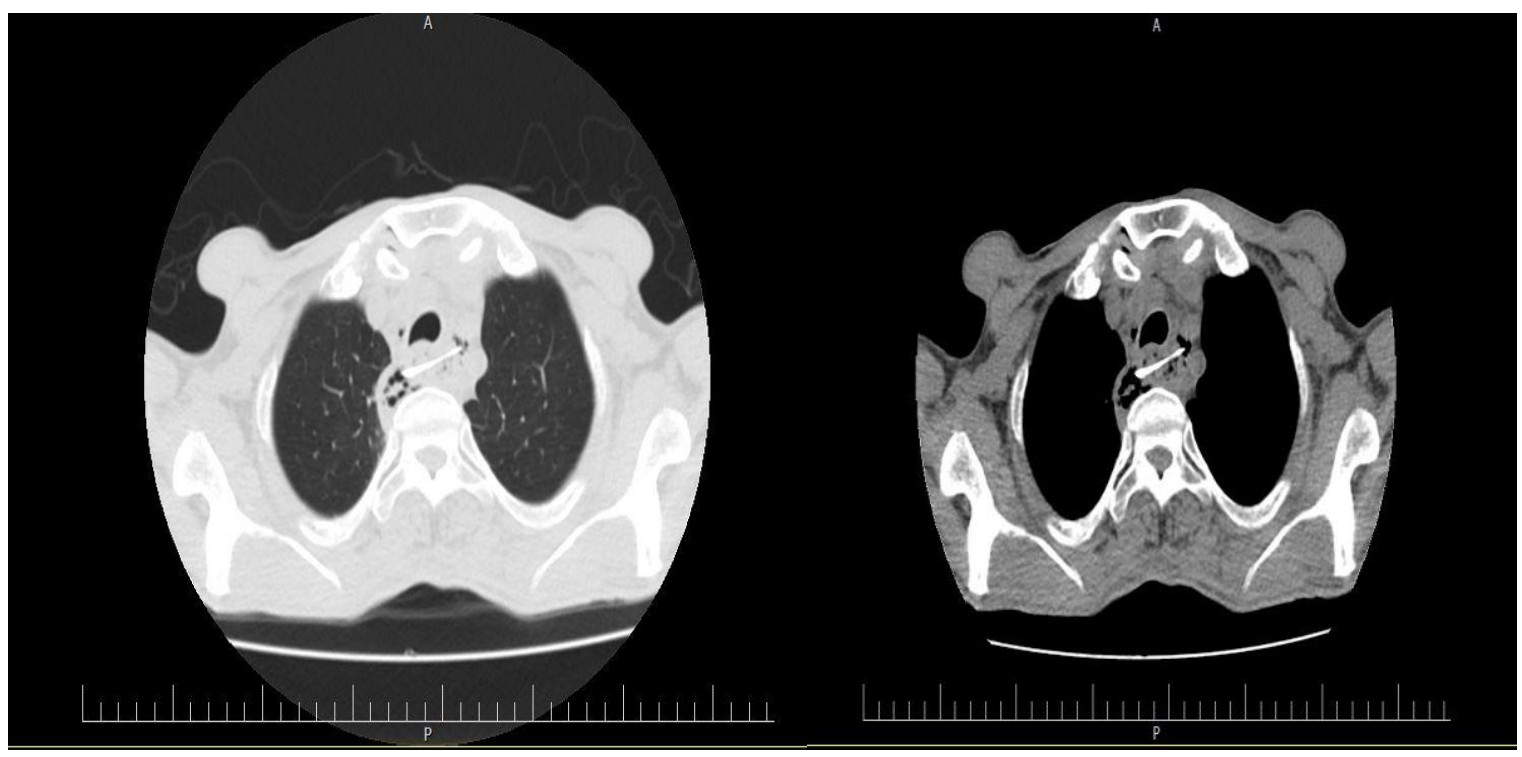

Figure 1. Rabbit bone segment in chest CT-Scan

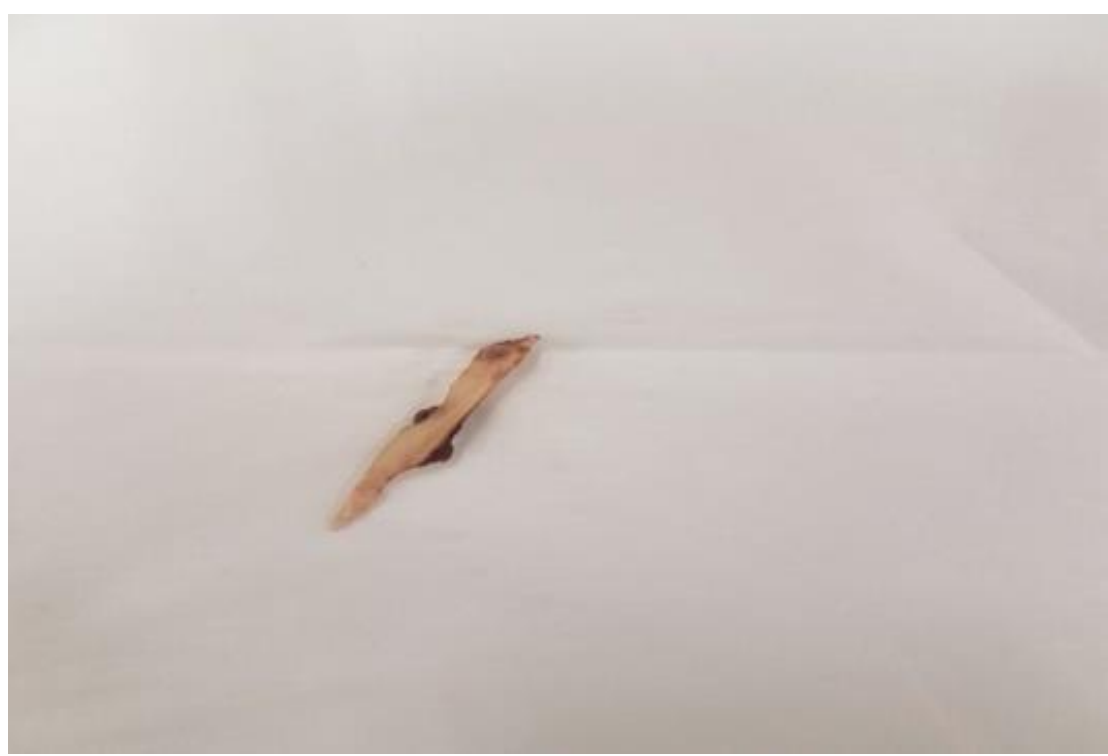

Figure 2. Image of rabbit bone after surgery 
Table 1. Blood tests upon admission and during hospitalization

\begin{tabular}{|c|c|c|c|}
\hline \multicolumn{2}{|c|}{ Admission date } & \multicolumn{2}{|c|}{ During hospitalization } \\
\hline Laboratory test & result & Laboratory test & result \\
\hline \multicolumn{2}{|c|}{ Blood test } & \multicolumn{2}{|c|}{ Blood test } \\
\hline PH & 7.30 & PH & 7.31 \\
\hline $\mathrm{PCO} 2$ & 38.8 & $\mathrm{PCO}_{2}$ & 36.1 \\
\hline $\mathrm{HCO} 3$ & 19.5 & $\mathrm{HCO}_{3}$ & 18 \\
\hline $\mathrm{BE}$ & -7.2 & $\mathrm{BE}$ & -7.8 \\
\hline BS & 328 & BS & 185 \\
\hline WBC & 110000 & WBC & 73000 \\
\hline $\mathrm{RBC}$ & 4.9 & $\mathrm{RBC}$ & 3.24 \\
\hline Neutrophil & $85 \%$ & Neutrophil & $66 \%$ \\
\hline Lymphocyte & $8.2 \%$ & Lymphocyte & $23.9 \%$ \\
\hline $\mathrm{Na}$ & 128 & $\mathrm{Na}$ & 145 \\
\hline $\mathrm{K}$ & 4.1 & $\mathrm{~K}$ & 4.4 \\
\hline BUN & 36 & BUN & 88 \\
\hline $\mathrm{Cr}$ & 1.1 & $\mathrm{Cr}$ & 1.7 \\
\hline Cpk & 184 & Cpk & 233 \\
\hline procalcitonin & 1.54 & procalcitonin & 8 \\
\hline Blood culture & Staph Epidermydis & Blood culture & - \\
\hline Sputum culture & pseudomonas & Sputum culture & - \\
\hline
\end{tabular}

Table 2. Urinary tests upon admission and during hospitalization

\begin{tabular}{|c|c|c|c|}
\hline \multicolumn{2}{|l|}{ Admission date } & \multicolumn{2}{|c|}{ During hospitalization } \\
\hline Laboratory test & result & Laboratory test & result \\
\hline Urinary analysis & & Urinary analysis & \\
\hline appearances & Semi-clear & appearances & Tube bide \\
\hline Blood & 3 & Blood & trace \\
\hline Protein & 1 & Protein & 1 \\
\hline Ketone & - & Ketone & 2 \\
\hline Glucose & - & Glucose & 3 \\
\hline WBC & $12-15$ & WBC & $1-4$ \\
\hline $\mathrm{RBC}$ & many & $\mathrm{RBC}$ & $5-6$ \\
\hline Urine culture & - & Urine culture & - \\
\hline
\end{tabular}

\section{Discussion}

Descending necrotizing mediastinitis (DNM) is characterized by complications resulting from odontogenic or oropharyngeal infections that spread to the cervical facial space. Finally, DNM descends to the mediastinum (8). Since the infection has a potential to spread, the early diagnosis of DNM is imperative (9). Otherwise, the risks of sepsis, septic shock, organ dysfunction, and even mortality are very high (4).

One of the main problems preventing the early diagnosis of this disease is its vague and non-specific symptoms, as its clinical manifestations usually appear in the form of severe pain around the neck, dyspepsia, anorexia, dyspnea, tachypnea, fever, dermatitis, odynophagia, bruising, crepitus, edema of the anterior of the neck, and chest pain (9). Chest pain is a distracting symptom that prevents specialists from diagnosing the disease early because they waste their time exploring other possible causes of chest pain while neglecting the possibility of DNM.

The differences between DNM complications and cardiovascular complications are difficult to detect. For instance, mediastinal infection as a complication of DNM involves symptoms such as chest pain, respiratory distress, and back pain (9). Esophageal rupturing is another complication associated with DNM (10). According to Cross et al. (2015), the severe 
chest pain due to DNM is similar to the pain that originates from a rupture of the aortic artery and myocardial infarction (11). Of course, causes of pulmonary heart disease should always be considered and evaluated, but other causes should not be overlooked (12). As a result, it is essential to assess the history of present illness and use clinical reasoning.

To treat odontogenic or pharyngeal mediastinitis, clinical manifestations should first be examined and separated from other diseases (13). Different approaches can be utilized to control and treat DNM, such as a combination of antibiotic therapy and infection control, thoracic surgery and drainage, hospitalization in an ICU, mechanical ventilation, and critical nursing care (4).

Streptococcus sp, as one of the most popular Grampositive bacteria, has a great role in the development of mediastinitis (14). Carbapenems and Clindamycin are the most common combination drugs used to treat mediastinitis, depending on the source of the infection (15).

Utilizing surgery and mediastinum drainage are alternative approaches for treating the disease, but their implementation is very challenging. However, many authors have suggested that the most effective management tool for the treatment of mediastinitis is to accurately and reliably consider the patient's medical history, clinical examinations, and clinical reasoning, followed by quick and sufficient drainage and providing support for hemodynamic status and the patient's nutrition status in ICUs and CT-scan repetition (14).

Based on previous studies, a large number of patients with DNM are at high risk due to underlying diseases such as diabetes, malnutrition, aging, kidney failure, liver cirrhosis, and underlying malignancies (16). Gender variables are also involved, with DNM mortality being higher in men than in women (2). Therefore, it is essential to review the patient's history of heart disease when assessing DNM. Nevertheless, some patients also develop the disease without any recognized complications (17).

\section{Conclusion}

This case report showed the importance of admission, extracting detailed and relevant history from patients, committing to the early treatment of these patients in the hospital, and employing a combination of antibiotic therapy and mediastinum drainage as a basic step in the treatment of patients with DNM. As a result, if early diagnosis, antibiotic therapy, thoracic surgery, proper monitoring, CT-scan imaging for differential diagnosis, and intervention are not initiated promptly, mediastinitis resulting from DNM can be lethal.

\section{Acknowledgment}

We sincerely thank the nursing staff of the ICU and the engineers of the information technology section of the Ayatollah Mousavi Hospital in Zanjan, as well as the Center for the Development of Clinical Research in Ayatollah Mousavi Hospital. Also, we thank the officials of Zanjan University of Medical Sciences, who provided the basis for this research.

\section{Conflict of Interest}

The authors declared that there is no conflict of interest regarding the publication of this case report.

\section{References}

1. Pastene B, Cassir N, Tankel J, et al. Mediastinitis in the intensive care unit patient: a narrative review. Clin Microb Infect. 2020;26(1):26-34. [DOI: 10.1016/j.cmi.2019.07.005] [PMID]

2. Wei D, Bi L, Zhu H, He J, Wang H. Less invasive management of deep neck infection and descending necrotizing mediastinitis: A single-center retrospective study. Medicine (Baltimore). 2017;96(15):e6590.

[DOI: 10.1097/MD.0000000000006590] [PMCID]

3. Elsahy TG, Alotair HA, Alzeer AH, Al-Nassar SA. Descending necrotizing mediastinitis. Saudi Med J. 2014;35(9):1123-6. [PMID] [PMCID]

4. Pota V, Passavanti MB, Sansone P, et al. Septic shock from descending necrotizing mediastinitis combined treatment with IgM-enriched immunoglobulin preparation and direct polymyxin B hemoperfusion: a case report. J Med Case Rep. 2018;12(1):55. [DOI: 10.1186/s13256-018-1611-5] [PMID] [PMCID]

5. Mazzella A, Santagata M, Cecere A, et al. Descending necrotizing mediastinitis in the elderly patients. Open Med (Warsaw, Poland). 2016;11(1):449-60.[DOI: 10.1515/med-20160080] [PMID] [PMCID]

6. Ochi N, Wakabayashi T, Urakami A, et al. Descending necrotizing mediastinitis in a healthy young adult. Ther Clin Risk Manag. 2018;14:201373 [DOI: 10.2147/TCRM.S176520] [PMID] [PMCID]

7. Ma C, Zhou L, Zhao JZ, et al. Multidisciplinary treatment of deep neck infection associated with descending necrotizing mediastinitis: a singlecentre experience. J Int Med Res. 2019;47(12):6027-40. [DOI: 10.1177/0300060519879308] [PMID] [PMCID]

8. Takanashi Y, Hayakawa T, Neyatani H, Funai K. Descending necrotizing mediastinitis complicating 
hyperimmunoglobulin E syndrome. Respirol Case Rep. 2016;4(4):e00165-e. [DOI: 10.1002/rcr2.165] [PMID] [PMCID]

9. Lloyd T, Tran VK. Acute mediastinitis as a complication of Epstein-Barrvirus. CJEM. 2016;18(2):149-51. [DOI: 10.1017/cem.2015.30] [PMID]

10. Choe JY, Kim JK, Lee DE, et al. Descending necrotizing mediastinitis after a trigger point injection. Clin Exp Emerg Med. 2017;4(3):182-5. [DOI: 10.15441/ceem.16.197] [PMID] [PMCID]

11. Cross MR, Greenwald MF, Dahhan A. Esophageal perforation and acute bacterial mediastinitis: other causes of chest pain that can be easily missed. Medicine. 2015;94(32):e1232-e. [DOI: 10.1097/MD.0000000000001232] [PMID] [PMCID]

12. Omura T, Mori H, Matsuoka M, Hori Y. Surgical management of descending necrotizing mediastinitis complicated by purulent pericarditis and Lemierre's syndrome. Am Surg. 2019;85(1):e47-e9. [PMID]
13. Sokouti M, Nezafati S. Descending necrotizing mediastinitis of oropharyngeal infections. J Dent Res Dent Clin Dent Prospects. 2009;3(3):82-5. [DOI: 10.5681/joddd.2009.021] [PMID] [PMCID]

14. Sumi Y. Descending necrotizing mediastinitis: 5 years of published data in Japan. Acute Med Surg. 2014;2(1):1-12. [DOI: 10.1002/ams2.56] [PMID] [PMCID]

15. Mabaso ET. A retrospective study of descending necrotizing mediastinitis of odontogenic origin. Johannesburg: university of the Witwatersrand; 2014.

16. Hidaka H, Ozawa D, Kuriyama S, et al. Risk factors for delayed oral dietary intake in patients with deep neck infections including descending necrotizing mediastinitis. Europe Arch Oto-Rhino-Laryngol. 2017;274(11):3951-8.[DOI: 10.1007/s00405-0174716-3] [PMID]

17. Yanik F, Karamustafaoglu YA, Yoruk Y. Management of a difficult infectional disease: Descending necrotizing mediastinitis. J Infect Dev Ctries. 2018;12(9):748-54. [DOI: 10.3855/jidc.10482] [PMID]

\section{How to Cite This Article:}

Zeraati M, Abdi M, Tahrekhani M. Necrotizing Mediastinitis Following Rabbit Bone Ingestion: A Case Report. J Adv Med Biomed Res. 2020; 28 (128):166-170

\section{Download citation:}

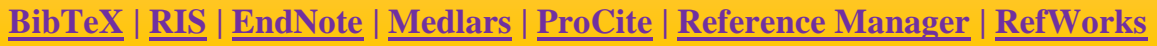

Send citation to:

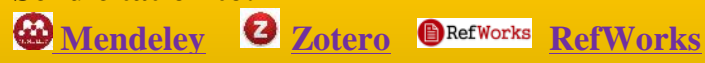

